What do professional learning policies say about purposes of teacher education?

\author{
Dr Aileen Kennedy \\ School of Education \\ University of Strathclyde \\ 141 St James Road \\ Glasgow \\ G4 OLT \\ SCOTLAND
}

aileen.kennedy@strath.ac.uk

$+44(0) 1414448061$ 


\title{
What do professional learning policies say about purposes of teacher education?
}

\author{
Abstract \\ Enhancing teacher learning is acknowledged globally as a key route to improving student \\ outcomes, thereby contributing to nation states' economic competitiveness (OECD, 2005). \\ This globally accepted policy 'hypernarrative' (Stronach, 2010) is driving reform of teacher \\ education policy internationally. This paper seeks to analyse some key features of \\ contemporary teacher professional learning policies in terms of the underpinning purposes of \\ education, in an attempt to make more explicit the purposes and potential implications of \\ particular policy choices. The analysis draws on literature related to the fundamental \\ purposes of school education, highlighting three broad, but distinct categories of 'purpose': \\ the socialisation function; the development of human capital; and 'subjectification' which \\ focuses on individual creativity (Biesta, 2009). While principally conceptual in nature, the \\ paper draws on the Scottish policy context in exemplifying the analysis, concluding that there \\ is a tendency towards socialisation and human capital functions, at the expense of \\ subjectification purposes.
}

\section{Introduction}

Issues of teacher quality, and therefore of teacher education, have gained prominence in recent years, and there is evidence worldwide of nation states' attempts to improve the quality of their teachers through reform of their teacher education policies. This article seeks to contribute to understandings of teacher learning policy through consideration of a number of different features which are apparent in contemporary policy making globally. It does this through the adoption of an analytical lens which outlines fundamental purposes of teacher education. While essentially conceptual in nature, the article draws on the Scottish 
policy context by way of illustrating the enactment of different perspectives within one particular policy context, with the intention of providing a framework for interrogating teacher professional learning policy which is applicable in other international contexts.

The article begins with an outline of the conceptual approach to the analysis and then provides an overview of the policy context of professional learning. It thereafter discusses four contemporary features of teacher professional learning policies, interrogating each in relation to what it reveals about fundamental purposes of teacher education, before concluding with a discussion of overall messages and an evaluation of the extent to which the analytical framework employed here might assist in the interrogation of teacher professional learning policy more widely.

\section{Approach}

The discussion on teacher professional learning advanced in this article is contextualised through consideration of the parallels between teacher learning and student learning, starting with fundamental ideas about purposes of education. There is, of course, a wide range of disciplinary perspectives that can be brought to bear on such an issue, dominated by philosophical and sociological perspectives, and it is generally acknowledged that there exists a range of purposes of education. Such purposes can be framed within different discourses, but three main ideas dominate:

1. The 'socialisation function' - 'ways in which, through education, we become members of and part of particular social, cultural and political 'orders' (Biesta, 2009, p. 40); 
2. The development of human capital, based on the premise that 'the more and better education that individuals possess, the better their returns in financial rewards and the better the national economy flourishes' (Gillies, 2011, p. 225);

3. Supporting and encouraging individual interests and creativity, or 'subjectification', that is, 'processes... that allow those being educated to become more autonomous and independent in their thinking and acting' (Biesta, 2009, p. 40)

It is not suggested that these three purposes are mutually exclusive, and in reality, aspects of all three purposes may exist concurrently. These purposes are, however, more often considered in connection with the purposes of school education for children, and they help us to see the ways in which children are positioned by society:

\begin{tabular}{|c|c|}
\hline Purpose of education & Children are positioned as... \\
\hline Socialisation & $\begin{array}{l}\text {... 'novice' members of society who need to be } \\
\text { inculcated into the culture and practices of that } \\
\text { particular society }\end{array}$ \\
\hline Human capital development & $\begin{array}{l}\text {... future workers who will contribute to the } \\
\text { enhancement of the country's economic wellbeing }\end{array}$ \\
\hline Subjectification & $\begin{array}{l}\text {... individual members of society whose interests and } \\
\text { talents should be fostered and encouraged with the } \\
\text { express intention of fostering independence and } \\
\text { creativity }\end{array}$ \\
\hline
\end{tabular}

Figure 1: Purposes of education and the positioning of children 
However, when applied to purposes of teacher learning, the identification of different purposes of education also forms a useful analytical tool for considering how teachers are positioned through professional learning policies:

\begin{tabular}{|l|l|}
\hline Purpose of (teacher) education & Teachers are positioned as... \\
\hline Socialisation & $\begin{array}{l}\text {... 'novice' members of the profession who need to be } \\
\text { inculcated into the existing culture and practices of the } \\
\text { profession, and thereafter help to maintain the status } \\
\text { quo }\end{array}$ \\
\hline Human capital development & $\begin{array}{l}\text { enhance the standing of the country through increased } \\
\text { success in international league tables of performance }\end{array}$ \\
\hline Subjectification & $\ldots$ autonomous educators who can contribute to the \\
& common good through the fostering of their own \\
& specific interests and talents in creative ways \\
\hline
\end{tabular}

Figure 2: Purposes of (teacher) education and the positioning of teachers

The socialisation function is evident in teacher professional learning through the identification of professional norms and the building of national professional identity. Just as with schooling for students, the socialisation purpose apparent in teacher professional learning policies can promote positive and activist professional identities, or can be used against them as a mechanism of control. The human capital function is evident in the way in which international measures of student achievement are used as proxy measurements for the success of individual nation states' education systems (and by implication, the success of their teachers), and therefore are seen to be measures of the human capital produced by 
these countries. Building human capital is regarded as a key means of ensuring that a state has sufficient appropriately educated citizens to contribute to its economic growth. Biesta's (2009) notion of subjectification, meanwhile, can be seen in teacher professional learning policies which value individual aspirations and to promote autonomy, creativity and teacher voice - a central aim in many new curriculum policies for compulsory schooling, as in the Curriculum for Excellence in Scotland (http://www.educationscotland.gov.uk/thecurriculum/whatiscurriculumforexcellence/).

Despite the identification of these three quite different purposes, it is not suggested that the analysis of teacher professional learning policies is as simple as categorising a particular country's policy/ies under one heading. It is a much more nuanced analysis that is required, recognising that different aspects of any individual country's teacher professional learning policy/ies might well reveal very different underpinning purposes of education in coexistence. What is important is to explore ways in which these purposes can be made explicit in an attempt to facilitate more strategic and purposeful matches between perceived fundamental purposes of teacher education, and policy decisions.

\section{The context of teacher professional learning}

The discourse of teacher professional learning appears to be driven by a globally accepted meta-narrative (Loomis et al., 2008). Stronach (2010, p. 10) argues that the power of global discourse on education 'has grown and so dominated national thinking about educational 'development' that it is necessary to regard the result as a kind of hegemonic 'hypernarrative'. This is illustrated through the emergence of a global trajectory which is currently dominated by a drive to seek policy solutions which will improve outcomes ('attainment') for students. Such evidence is to be found in the increasing number of international reports from organisations such the Organisation for Economic Cooperation 
and Development (OECD), including: 'Teachers Matter' (OECD, 2005), the 'Teaching and Learning International Survey' (TALIS) (OECD, 2008), the EU-commissioned secondary analysis of the TALIS dataset (Scheerens, 2010) and the McKinsey reports (Barber \& Mourshed, 2007; Mourshed, Chijioke \& Barber, 2010). Most recently, following the publication of the 2012 results, evidence of the power of PISA has been seen in headlines such as:

Scaling education heights in Pisa; Singapore's strong performance in the international benchmarking test validates recent shifts in teaching (The Straits Times, Singapore, 5 December 2013)

O.E.C.D. official warns West on education gaps; After Asians dominate global tests, politicians in Britain take stock (International New York Times, USA, 9 December 2013)

These international assessment programmes, and the resulting country rankings, have been used to substantiate the globally persuasive claim that teachers are the defining factor in student progress. While appealing to notions of 'common sense' and global competition, Stronach $(2010$, p. 10) contends that such deference to international measures is creating a 'global homogenizing effect' where international assessment programmes have become the accepted indicators of 'cultural performance' (ibid.). This being the case, and being accepted in a largely uncritical manner despite growing critique (Kreiner, 2011), then the logical policy solution seems to have been to reform teacher education, leading to attempts to identify 'what works' in terms of raising teacher quality through teacher education. To exemplify from a national perspective, a recent wholesale review of teacher education in Scotland reported in January 2011. The very first paragraph of the first page of the report demonstrates the pervasive global influence on developments: 
Over the past 50 years, school education has become one of the most important policy areas for governments across the world. Human capital in the form of a highly educated population is now accepted as a key determinant of economic success. This has led to countries searching for interventions which will lead to continuous improvement and to instigate major programmes of transformational change. Evidence of relative performance internationally has become a key driver of policy. That evidence suggests, perhaps unsurprisingly, that the foundations of successful education lie in the quality of teachers and their leadership. (Donaldson, 2011, p. 2).

Teacher professional learning, just as with student learning, is therefore constructed and shaped in such a way as to further particular political ideologies, be they global, national, local, or a combination of levels of influence. Given the significant political influence on teacher professional learning policy internationally, it is argued that just as student curricula are, or at least ought to be, subject to debate about purpose and rationale, so too should the policies that govern and shape teacher professional learning.

This leads us to consider how teacher education is governed, and who makes the key policy decisions. In Scotland, the governance of teacher education, while ultimately in the hands of the Scottish Government, is increasingly enacted through partnership working, or 'network governance'. While arguably more democratic on the surface, a convincing critique can be offered that would suggest that this is a much more insidious way of Government ensuring that no one stakeholder assumes dominance (Kennedy \& Doherty, 2012). Offe (2009, p. 555) 
describes network governance as 'state-organized unburdening of the state' where explicit control moves from government to governance, but where government retains overall control of the ways in which the network or partnerships operate. Allied to this critique, is the concern that in any network or partnership, detailed knowledge of, or concern about, how teachers learn is not likely to be present in equal measure across all partner groups, and assumptions about fundamental purposes of teacher education may vary across, and indeed within, these groups.

In summary, the case of Scottish teacher education policy seems to illustrate the contribution of both international and national political influences, both of which point towards a view that schooling is the key mechanism by which nation states will achieve economic growth: an explicit human capital purpose. In order to improve the outcomes of schooling, the inputs, that is the teaching, needs to be of better quality. This is perhaps a somewhat crude summary, and should be acknowledged that while nation states in some respects are influenced by the same international pressures, their means of reforming teacher education are bound up with more local, contextual factors, resulting in what Ozga \& Lingard (2007), drawing on Appadurai (1996), refer to as 'vernacular globalisation'. It is perhaps in the vernacular globalisation context that we see more clearly the interaction between the three purposes of schooling evidenced within teacher professional learning policies.

There now follows consideration of four features which figure prominently in the international policy meta-narrative as means of improving teacher quality, and are apparent to varying degrees in teacher professional learning policies across the developed world: standards-based models; collaborative learning; Masters level learning; and the measurement of impact of professional learning. These four features are analysed in relation 
to their capacity to support a particular view on the purpose of teacher education, using the framework outlined earlier.

\section{Teacher professional learning: a standards-based approach}

The increased international focus on teacher quality has brought with it an increased focus on the use of professional standards as a means of encapsulating expressions of what it means to be a good (or good enough) teacher. While there exist some very positive reasons for the existence of teacher professional standards, not least their contribution to the professionalisation of teaching through their capacity to make teachers' work more transparent, there is, nonetheless, a plethora of literature which critiques their functions in a more negative way. Sahlberg (2011, p. 177) suggests that 'a widely accepted-and generally unquestioned-belief among policymakers and education reformers is that setting clear and sufficiently high performance standards for schools, teachers, and students will necessarily improve the quality of desired outcomes'. This belief has been translated into policy measures which are not informed sufficiently by a rigorous evidence base, and the link between the publication of standards-based statements and their impact on teachers' practice, and ultimately the educational achievement of students, has arguably not yet been subjected to sufficient empirical scrutiny.

The discourse of 'standards' tends to be used in a fairly uncritical way, for example, in Scotland, where a recent review of the professional standards reveals a range of different things happening under the guise of a 'suite of professional standards'. In late 2012, the General Teaching Council for Scotland (GTCS) published their revised suite of professional standards:

- The Standards for Registration (GTCS, 2012a) 
- The Standard for Career-Long Professional Learning (GTCS, 2012b)

- The Standards for Leadership and Management (GTCS, 2012c).

These three sets of standards appear to have very different purposes and statuses. For example, student teachers must meet the Standard for Provisional Registration in order to be granted provisional registration with the GTCS and therefore to be able to commence the induction year. And At the end of the induction year they must meet the Standard for Full Registration (SFR) in order to be granted full registration with the GTCS. In addition, teachers from outside of Scotland who wish to be registered with the GTCS must also meet the SFR. Thereafter, the SFR remains the 'baseline standard of professional competence which applies to teachers throughout their career' (GTCS, 2012a, p. 4). In effect, this means that the SFR has statutory, licencing status and is used to determine whether or not a teacher becomes, and remains, fit to be registered to teach in Scotland. This reflects a clear human capital purpose, illustrating the perceived need to ensure that workers, in this case teachers, are equipped to contribute to governmental aims by demonstrating practice that is at least at a level considered to be baseline competence. The mandatory nature of the standards for registration may also help to fulfil a socialisation purpose through prioritising what is deemed to be most important.

The statutory, baseline nature of this standard is in direct contrast with the aspirations espoused for the Standard for Career-Long Professional Learning (SCLPL) which unlike the other standards does not provide lists of indicative 'professional actions', which inevitably give standards a behaviourist, competence-based focus. The SCLPL 'provides an opportunity for teachers to progress, enrich, develop and enhance their practice, expertise, knowledge, skills and professional values' (GTCS 2012b, p. 5), revealing much more of a subjectification perspective. Given that there is no accompanying statutory power and that it does not relate 
to any particular role or status, it is reasonable to assume that the intention of the SCLPL is to provide a framework for fully registered teachers who are not in, or seeking, leadership posts. This then raises the question of whether or not the SCLPL is indeed a 'standard' in the true sense of the word, when it cannot 'measure' standard practice. Is it perhaps the case that given the global focus on standards for teaching, which we have become unable to think outside of the discourse provided by a standards-based approach?

Sachs (2003) warns of the potential danger to teachers in accepting the argument that standards provide a useful framework for scaffolding professional learning, suggesting that rather than being helpful, unquestioning acceptance of the use of standards can result in teachers being socialised in particular ways; becoming 'complicit in their own exploitation and the intensification of their work' as 'professionalism under the guise of standards becomes a tool for employers demanding more of teachers' (p. 184). Or, as Stanley and Stronach (2013) warn, standards can be 'a form of power applied by state agencies to professional work and identity' (p. 6). While this is arguably not the intended purpose of the revised standards in Scotland, the possibility of them being used to the advantage of employers does clearly exist. It is not suggested that this outcome is necessarily a conscious one, but that the combination of unquestioning acceptance and a discourse which promotes standards as unequivocally a good thing for teacher quality, can serve unwittingly to intensify teachers' work, thereby revealing a very clear human capital purpose enacted through a socialisation perspective. It is interesting to note that the consultation on the revised professional standards in Scotland did not ask if the adoption, or continued adoption, of a standards-based framework was a good thing, rather it asked: 'How clear is this description of the reasons for introducing revised standards and of their content?' This situation is echoed in Bourke, Ryan and Lindstone's (2013) analysis of the Australian context 
where 'no debate actually exists about the usefulness of standards; their implementation has become taken for granted' (p. 409).

The Scottish context also provides a unique combination of standards which while described as a 'suite', thereby implying a level of coherence, actually illustrate a range of purposes, functions, origins and possibilities, possibly suggesting a lack of clarity as to their fundamental purpose. It is in this complex crucible that we see Ozga and Lingard's (2007) vernacular globalisation at work, where various aspects of the suite of standards develop in different ways in response to a range of historical, cultural and professional conditions.

\section{Teacher professional learning: a collaborative endeavour}

In contrast to the individualised focus supported through professional standards, there also exists a fairly powerful emphasis on collaborative professional learning in many states' professional learning policies. A key determinant in public policy across the globe at the moment is the difficult economic situation. It has been argued that in education, teacher professional learning is one of the first casualties of spending cuts as it is not seen to have the same level of priority as 'front-line' services. One way round this economic challenge has been to limit the spending on teacher CPD activities and events through promoting alternative forms of learning which can be carried out in-situ: collaborative learning in socalled learning communities has been promoted as a viable and justifiable alternative.

The benefits of collaborative professional learning are well reported, in particular, Cordingley et al's (2005) systematic review which concludes that the most effective CPD is both collaborative and sustained over a period of time. However, productive collaboration requires purposeful engagement and cannot simply be left to chance. The culture of local contexts which were the unit of focus in James et al.'s work can serve either to support or to 
inhibit collaborative learning. James et al. found that while networks of learners were perceived to be valuable, it was acknowledged that these views are usually relatively subjective, and that the worth and value of particular networks tends to be perceived differently by people in different positions. While such models of professional learning have their attractions in managerial terms, they can have their drawbacks too, principally relating to the value-base of participants, the acknowledgement of different and potentially conflicting values and the potential lack of challenge to dominant views within the network or community. Hadar and Brody $(2013$, p. 157) suggest that in addition to positive outcomes accrued by teachers working in 'professional development communities', the collaborative endeavour can 'nurture alliances based on collegial support for resistance to learning and professional growth', going on to illustrate that 'In our case, those alliances helped some participants to protect their existing practice against outside encouragement to change'; performing a powerful socialisation function. And Perhaps of even greater concern is the capacity for collaborative professional learning to be enacted as a form of 'contrived collegiality' which Czerniawski (2013, p. 385), drawing on Hargreaves (1992), relates to the existence of 'highly regulated, compliant and audited school systems' which seek to impose change from the outside, thereby ignoring the need to identify and address teachers' own values and beliefs.

It is clear to see how such collaborative learning communities or networks might serve to fulfil a socialisation function, given the explicit influence of power and hierarchies in such situations. This is not necessarily to say that socialisation is a bad thing per se, but merely to acknowledge that a key underlying function of collaborative learning is its capacity to socialise participants into dominant ways of working and thinking. 
While there is a plethora of research which highlights the positive effects of collaborative learning (e.g. Darling-Hammond et al., 2009), it is important too, to recognise the potential limitations of collaborative learning. In her 'Best Evidence Synthesis' of the relationship between teacher professional learning and student outcomes, Timperley (2008, p. 29) concludes that teachers should be given 'opportunities to process new learning with colleagues', however, she cautions that such learning 'requires knowledgeable expertise in facilitating productive professional learning'. While some collaborative learning endeavours can be empowering, leading to sustainable professional learning and positive impact on students, it is important to recognise the need to ensure that such collaborative opportunities are well organised, supported and led, and that the socialisation function alone does not assume primary importance.

\section{Teacher professional learning: a Masters level activity}

There has been significant international interest in promoting the idea of teaching as a Masters level profession, driven in no small part by a recognition that some of the highest performing countries in international assessment programmes place value on their teachers being educated to Masters level. Principal among these countries is Finland, where teachers must have a Masters qualification in order to be appointed to a permanent post. In the Scottish context, the recently published report of the National Partnership Group (NPG) (Scottish Government 2012), points to the McKinsey reports as evidence that the 'best' education systems internationally are increasingly working towards teaching being a Masters level profession. In announcing the publication and endorsement of the NPG Report, Alasdair Allan, Minister for Learning said:

International comparisons show the positive impact that a Masters level qualification can have on education. That's why we will give the same 
opportunities to teachers in Scotland, building on the extremely high

standards that already exist.

Scottish Government Press Release, 06/11/12.

This line of reasoning points very much to a focus on quality teachers as a means of generating human capital. That is, the assumption that if Finland can produce high quality teachers through insisting that they are Masters qualified, then the same approach should bear similar fruit in the Scottish context: evidence of a policy borrowing approach. However, there is little evidence focusing on what it is about Masters level teacher education that results in teachers producing better 'outcomes' for their students (Brooks et al., 2012). The drive towards Masters level learning is not specific in policy terms in relation to what kind of learning should be taking place at Masters level. It could be suggested that general learning at Masters level, regardless of subject or content, will support teachers to become better educated in a general sense and to be able to be more critical in their outlook and therefore to have a stronger professional voice, that is, to support subjectification purposes. However, it could equally well focus on improving subject or pedagogical knowledge, with the express intention of improving student outcomes in Government-identified priority areas, as in the English 'Masters in Teaching and Learning' (MTL) model (Bailey \& Sorensen, 2013), thereby suggesting more of a human capital purpose. A third possible intended outcome for Masters level teacher learning, and certainly one that is strongly suggested in the Finnish model (Simola, 2005), is that to have teaching as a Masters profession would raise the status of teachers and teaching; implying a socialisation perspective.

This lack of clear purpose in relation to the potential function and structure of Masters level teacher education betrays an unquestioned policy solution that seems to have been universally accepted as a good thing, despite a paucity of evidence as to its effect. Howe 
(2013, p. 62) suggests that this is more to do with market forces than it with improving teaching:

In light of global neoliberal and neoconservative agendas fulfilling international comparisons, with calls for improving teacher standards and educational accountability, perhaps the international trend towards master's degrees becoming the new 'gold standard' of teacher accreditation is at least partially due to external market forces, with little to do with more effective teaching.

This points towards a need for more empirical evidence regarding the purpose, nature and impact of Masters level teacher education, and a deeper interrogation of the intentions of Master-level learning (understood as enhanced intellectual capacity) as opposed to Masters qualifications (credentialism).

\section{Teacher professional learning: making a measurable impact}

Given the growing emphasis on, and investment in, teacher professional learning it is perhaps hardly surprising that there have been widespread calls for greater evidence of the impact of such investment. Yet such attempts to measure impact do not come without farreaching implications

Sahlberg (2011, p. 177) asserts that such attempts at measuring impact have led to a particular range of policy solutions: 'Making schools and teachers accountable for their students' learning outcomes has led to the introduction of education standards, indicators and benchmarks for teaching and learning, aligned assessments, and testing and prescribed curricula'. This range of practices and procedures fits clearly within a managerial approach to 
teacher professionalism, yet is subject to significant critique in relation to the way in which it shapes what is valued in education. Biesta (2009) warns of the influence that measuring educational outcomes can have on its perceived value:

'The rise of a culture of performativity in education - a culture in which means become ends in themselves so that targets and indicators of quality become mistaken for quality itself - has been one of the main 'drivers' of an approach to measurement in which normative validity is being replaced by technical validity.'

(Biesta, 2009, p. 36)

In Scotland, the Donaldson Report (Donaldson, 2011, p. 98), recommends that 'at the outset of any CPD activity, the intended impact on young people, and the aspects of the relevant professional standard the teacher will improve as a result of the activity, should be clear'. This suggests a simple input/output correlational model of teacher professional learning, something that Opfer and Pedder (2011), amongst others, dispute, arguing that teacher professional learning is a much more complex phenomenon than could be described and/or measured in this way.

However, Scotland is not alone in its attempts to raise the importance of measuring impact of teacher learning and ultimately teacher performance. In the United States there has been an exponential growth in the use of 'value added teacher evaluation' model (see Chetty, Friedman \& Rockoff, 2011), which supports both human capital and socialisation purposes of teacher education, but undoubtedly thwarts notions of subjectification. Critics of the valueadded teacher evaluation approach point to the unintended effects of such wholesale performativity measures, warning that being measured in such a way is likely to discourage 
teachers from working with students who are less likely to score highly on standardised tests (Mangiante, 2011). This approach, focusing very much on a human capital view of teacher education, arguably works against democratic principles and the furthering of a wide, generic education which emphasises skill and attitudes, and not just knowledge.

While there do exist, of course, other means of 'measuring' impact, such as observational data and parent/student surveys, the dominant positivist culture drives us to account for ourselves to Government in a language that is more easily understood - that of numerical representation of quality. There therefore exists a tension between measures of impact which might support a subjectification perspective on teacher education, and the dominant numerical, standardised test score approach which is much more likely to support a human capital perspective on teacher education.

\section{Conclusions}

The foregoing discussion of purposes of teacher education, as explored in the four features identified as dominant in current policy, suggests no one dominant purpose of teacher education being apparent. This is probably as one might expect, as there naturally exist several purposes of and for education. However, what is noticeable is the dominance of human capital and socialisation perspectives at the expense of a subjectification perspective.

What this article seeks to do is to draw attention to the potential purposes fulfilled by the range of policy 'solutions' discussed, with a view to encouraging all stakeholders involved in policy development and enactment to approach the project of teacher education reform from a more explicitly critical stance. The discussion has also tried to identify areas where we arguably need greater, or different, empirical evidence in order to be more confident that the policy solutions adopted will actually have a chance of achieving the desired policy 
goals. Specifically, we need better empirical evidence about: the link between standardsbased professional learning policies and improvements in student outcomes; teachers' lived experiences of professional learning policies in comparison with policy-makers' espoused aims; and the possibilities and efficacy of means of measuring impact resulting from teacher professional learning.

Analysing dominant teacher education policy solutions through the lens of 'purposes of teacher education' will not ever enable us to fully understand teacher education reform. What it does contribute, however, is another means of interrogating purposes and possible outcomes of particular policy solutions, and at the very least, provides us with another means of articulating some of the more complex and nuanced aspects of a very complicated and fast-moving policy field.

\section{References}

Appadurai, A. (1996). Modernity at large: Cultural dimensions of globalisation. Minneapolis, MN: University of Minnesota Press.

Bailey, M. \& Sorensen, P.(2013). Reclaiming the ground of master's education for teachers: lessons to be learned from a case study of the East Midlands Masters in Teaching and Learning, Journal of Education for Teaching: International research and pedagogy, 39:1, 39-59.

Barber, M. \& Mourshed, M. (2007). How the world's best-performing schools come out on top. London: McKinsey \& Company.

Biesta, G. (2009). Good education in an age of measurement: on the need to reconnect with the question of purpose in education. Educational Assessment, Evaluation and Accountability, 21(1), 33-46. 
Bourke, T., Ryan, M.E. \& Lidstone, J. (2013). Reflexive professionalism: reclaiming the voice of authority in shaping discourses of education policy. Asia-Pacific Journal of Teacher Education, 41(4), 398-413.

Brooks, C., Brant, J., Abrahams, I. \& Yandell, J. (2012). Valuing initial teacher education at Master's level, Teacher Development: An international journal of teachers' professional development, 16(3), 285-302.

Chetty, R., Friedman, J. \& Rockoff, J. (2011). The long-term impacts of teachers: teacher value-added and student outcomes in adulthood. Cambridge, MA: National Bureau of Economic Research.

Cordingley, P., M. Bell, S. Thomason, \& A. Firth. (2005). The impact of collaborative continuing professional development (CPD) on classroom teaching and learning. Review: How do collaborative and sustained CPD and sustained but not collaborative CPD affect teaching and learning? In Research evidence in education library. London: EPPI-Centre, Social Science Research Unit, Institute of Education, University of London.

Czerniawski, G. (2013). Professional development for professional learners: teachers' experiences in Norway, Germany and England. Journal of Education for Teaching, 39(4), 383-399.

Darling-Hammond, L., Wei, R.C., Andree, A., Richardson, N. \& Orphanos, S. (2009). Professional learning in the learning profession: A status report on teacher development in the U.S. and abroad. Dallas, Texas: National Staff Development Council. DfE (2013). Teachers' Standards. Department for Education: UK Government.

Donaldson, G. (2011). Teaching Scotland's future: A report of the review of teacher education in Scotland. Edinburgh: Scottish Government.

GTCS (2012a). The Standards for Registration: mandatory requirements for Registration with the General Teaching Council for Scotland. Edinburgh: GTCS. 
GTCS (2012b). The Standard for Career-Long Professional Learning: supporting the development of teacher professional learning. Edinburgh: GTCS.

GTCS (2012c). The Standard for career-long professional learning: Draft August 2012. Edinburgh: GTCS.

Gillies, D. (2011). State education as high-yield investment: Human Capital Theory in European policy discourse. Journal of Pedagogy, 2(2), 224-245.

Hadar, L.L. \& Brody, D.L. (2013). The Interaction between group processes and personal professional trajectories in a professional development community for teacher educators, Journal of Teacher Education, 64(2), 145-161.

Hargreaves, A. (1992). "Contrived Collegiality: The Micro-politics of Teacher Collaboration." In Managing Change in Education - Individual and Organizational Perspectives, edited by N. Bennet, M. Crawford, and C. Riches. London: Paul Chapman Publishing.

Howe, E.R. (2013). Alternatives to a master's degree as the new gold standard in teaching: a narrative inquiry of global citizenship teacher education in Japan and Canada. Journal of Education for Teaching: International research and pedagogy, 39:1, 60-73.

James, M., McCormick, R. \& Marshall, B. (2006). Learning how to learn - in classrooms, schools and networks. TLRP. (http://www.tlrp.org/pub/documents/no17 james.pdf). Kennedy, A. \& Doherty, R. (2012). Professionalism and partnership: Panaceas for teacher education in Scotland? Journal of Education Policy, 27(6), 835-848.

Kreiner, S. (2011). Is the foundation under PISA solid? A critical look at the scaling model underlying international comparisons of student attainment. Research Report 11/1, Department of Biostatistics University of Copenhagen. https://ifsv.sund.ku.dk/biostat/biostat annualreport/images/c/ca/ResearchReport2011-1.pdf 
Loomis, S., Rogriduez, J. \& Tillman, R. (2008) Developing into similarity: Global teacher education in the twenty-first century, European Journal of Teacher Education, 31(3), 233-245.

Mangiante, E. (2011). Teachers matter: Measures of effectiveness in low-income minority schools. Educational Assessment, Evaluation and Accountability, 23(1), 41-63.

Mourshed, M., Chijioke, C. \& Barber, M. (2010) How the world's most improved school systems keep getting better. London: McKinsey \& Company.

OECD. (2005). Teachers matter. Paris: OECD.

OECD (2008). Teaching and learning international survey (Paris, OECD).

Offe, C. (2009). Governance: "An empty signifier"? Constellations 16, no. 4: 550-562.

Opfer, V.D. \& Pedder, D. (2011). Conceptualizing Teacher Professional Learning. Review of Educational Research, 81(3), 376-407.

Ozga, J. \& Lingard, B. (2007). Globalisation, education policy and politics (pp. 65-82). In B. Lingard \& J. Ozga (Eds.) (2007) The Routledge Falmer reader in education policy and politics. London: Routledge Falmer.

Sachs, J. (2003). Teacher professional standards: controlling or developing teaching? Teachers and Teaching: theory and practice, 9(2), 175-186.

Sahlberg, P. (2011). The fourth way of Finland. Journal of Educational Change, 12(2), 173184.

Scheerens, J. (Ed.). (2010). Teachers' professional development: Europe in international comparison. European Union: Luxembourg. http://ec.europa.eu/education/schooleducation/doc/talis/report en.pdf

Scottish Government (2012). Report of the National Partnership Group. Edinburgh: Scottish Government.

Simola, H. (2005). The Finnish miracle of PISA: Historical and sociological remarks on teaching and teacher education. Comparative Education, 41(4), 455-70. 
Stanley, G.E. \& Stronach, I. (2013). Raising and doubling standards in professional discourse: a critical bid. Journal of Education Policy, 28(3), 291-305.

Stevens, D. (2010). A Freirean critique of the competence model of teacher education, focusing on standards for qualified teacher status in England. Journal of Education for Teaching, 36(2), 187-196.

Stronach, I. (2010) Globalizing education, educating the local: How method made us mad. Abingdon: Routledge.

Tatto, M.T. (2007). (Ed.). Reforming teaching globally. Oxford: Symposium Books.

Timperley, H. (2008). Teacher professional learning and development. Geneva: International Bureau of Education. 